\title{
Distribuição de dividendos e valor de empresas listadas na B3
}

\author{
Gabriel de Amorim ${ }^{1}$ (D) , Nilton César Lima² ${ }^{\text {(D) }}$, Antônio Carlos Brunozi Júnior ${ }^{3}$ (D) \\ 1,2Universidade Federal de Uberlândia, Uberlândia-MG, Brasil. \\ ${ }^{3}$ Universidade Federal de Viçosa, Viçosa-MG, Brasil.
}

$\bigotimes$

'adm.gamorim@gmail.com

2niltoncesar@ufu.br

${ }^{3}$ acbrunozi@yahoo.com.br

Editado por:

Orleans Silva Martins

Paulo Roberto da Cunha

\section{Resumo}

Objetivo: Pela tendência dos mercados de ações internacionais sugere-se que empresas que não distribuem dividendos são mais bem avaliadas pelo mercado do que empresas que efetuam uma pequena distribuição de lucros, enquanto as empresas com maiores distribuições de dividendos são melhor avaliadas. Esse cenário na literatura foi descrito como Relação em "Formato J". De posse desse aspecto de mercado, este estudo objetivou identificar se há a existência do "Formato J" na relação entre dividendos e valor das empresas no mercado de capitais brasileiro.

Método: Dividiu-se uma amostra de 3.556 observações de 271 empresas, no período de 1996 a 2018, entre empresas não pagadoras de dividendos (DIVO) e pagadoras de dividendos, sendo essas últimas divididas em cinco grupos classificados de acordo com o dividendo distribuído (DIVI a DIV5). Realizou-se a análise do formato da relação através das medianas dos grupos e os testes estatísticos para se estabelecer a relação estatística entre o dividendo distribuído e o valor das empresas ( $q$ de Tobin).

Resultados: Foi constatado que o mercado brasileiro não apresenta o "Formato J". Dessa forma, as empresas não pagadoras de dividendos apresentaram piores valores do que aquelas que distribuíram dividendos aos acionistas - sendo que apresentaram melhores valorizações as empresas que distribuíram maiores volumes de lucros aos detentores de ações. Adicionalmente, confirmou-se a relevância dos dividendos no valor das empresas no mercado brasileiro.

Contribuições: O trabalho avança na discussão de dividendos e valor de empresas no Brasil ao propor uma nova abordagem estatística ao tema, categorizando empresas por suas políticas distintas de distribuições de lucro e evidenciando a clientela pródividendos no mercado brasileiro.

Palavras-chave: Dividendos; Valor de empresas; "Formato J".

Como citar:

Amorim, G., Lima, N. C., \& Brunozi Júnior, A. C. (2021). DISTRIBUIÇÃO DE DIVIDENDOS E VALOR DE EMPRESAS LISTADAS NA B3. Advances in Scientific and Applied Accounting, 14(3). Recuperado de https://asaa.anpcont.org.br/index.php/asaa/article/view/754 


\section{Introdução}

A existência ou não da relação entre os lucros distribuídos e o valor das empresas é assunto comumente tratado no campo das ciências sociais aplicadas (Zanon et al., 2017), sendo a distribuição dos lucros para os acionistas, aqui tratada como dividendos, uma das decisões mais importantes da gestão, dado que os dividendos são concorrentes pelos mesmos recursos destinados ao investimento em novos projetos (Ehrhardt \& Brigham, 2014; Santos \& Galvão, 2015). Outrossim, eles são o principal ponto de atenção dos investidores durante o processo de análise de seus investimentos (Ribeiro, 2010). Todavia, não há um aparente consenso sobre suas implicações no valor das empresas (Baker \& Weigand, 2015; Litzenberger \& Ramaswamy, 1982).

Defendendo a relevância dos dividendos, que é a sua relação no valor de mercado das empresas, Lintner (1956) se baseia na crença de que acionistas preferem taxas estáveis de distribuição de lucros a distribuições oscilantes em taxas e em prazos. Segundo o referido autor, o mercado estabeleceria um prêmio para ações que mantém estabilidade de distribuição ou de crescimento. Gordon (1959), por sua vez, credita a valorização das ações de empresas com maior distribuição de dividendos à aversão ao risco futuro por parte dos investidores.

Há outras abordagens aplicadas para explicar a relação dos dividendos no valor das empresas. A Teoria de Agência (Jensen \& Meckling, 1976), o efeito clientela (Miller \& Modigliani, 1961), a Teoria da Preferência Tributária (Elton \& Gruber, 1970), o "Efeito Disposição" (Shefrin \& Statman, 1984) e, mais recentemente, a hipótese do Catering (Baker \& Wurgler, 2004), que trazem mais possibilidades para se compreender a relação dos dividendos com o valor da firma.

A importância de se conhecer a relação entre os dividendos e o valor da firma é, principalmente, de cunho decisório. Van Horne (1998) e Rappaport (2001) argumentaram que a criação de valor para o acionista deve ser o principal objetivo da gestão das empresas. Van Horne (1998) discorreu, ainda, que o valor é representado pelo preço de mercado de uma ação ordinária de uma empresa, que está relacionado com decisões de investimento, financiamento e dividendos.

Nesse sentido, o estudo da relação entre os dividendos distribuídos e o valor das empresas é um tema recorrente na literatura de finanças, com diversas óticas apresentadas para analisar essa questão. Litzenberger e Ramaswamy
(1982), baseando-se na expectativa de dividendos futuros, encontraram evidências de que a valorização das ações é positivamente relacionada à distribuição dos dividendos, sendo esta relação não linear. Para os autores, o dividend yield contém características informacionais que influenciam a expectativa dos pagamentos futuros.

Já Baskin (1989) analisou a influência direta e indireta dos dividendos nas oscilações de preços de ações no mercado norte-americano. Suas conclusões apontaram para a capacidade de o dividendo isoladamente afetar os preços dos títulos. Tal constatação também foi discutida em Fama e French (2001), que reportam uma queda no número de empresas que distribuem dividendos, no mercado americano, devido ao crescente número de empresas pequenas, com baixa lucratividade e com boas oportunidades de crescimento.

Pinkowitz et al. (2006) apontaram que a relação entre - caixa e o valor da empresa é baixa em países com menor proteção para os investidores, enquanto a relação entre os dividendos e o valor da empresa é mais fraca em países com maior proteção, corroborando à Teoria de Agência. Os autores apontaram dois componentes de proteção para os investidores: "um componente de direitos legais, pelo qual os investidores recebem direitos legais e um componente de enforcement, pelo qual a qualidade das instituições de um país determina até que ponto esses direitos são respeitados e cumpridos" (op. cit., p. 2726, tradução nossa).

DeAngelo et al. (2008) concluíram que os principais impulsionadores da política de distribuição de fluxo de caixa livre são a busca pela redução da assimetria informacional no mercado, os custos de agência e problemas de mensuração de riscos futuros. Os autores também identificaram que questões de sinalização ao mercado, demandas da clientela de investidores, benefícios fiscais ou heurísticas de comportamento dos investidores, têm uma menor significância na distribuição dos lucros.

Forti et al. (2015) e Ferreira Júnior et al. (2010) apontaram para fatores relacionados às abordagens de Lintner, de Agência e de características das empresas, como influenciadores da decisão de distribuição de dividendos, confirmando a existência da relação entre dividendos e valor.

Por sua vez, Silva Júnior e Machado (2015) buscaram 
compreender a política de dividendos no valor das ações de empresas negociadas no Brasil. Os resultados permitiram concluir que a política de dividendos brasileira é significante para determinar a volatilidade dos preços das ações, sendo que quanto maior o dividendo por ação distribuído, menor o risco enfrentado pelo acionista.

Dado o exposto, uma característica recorrente aos estudos da relação dividendos/valor é a utilização de modelos estatísticos voltados à média das amostras ou à relação com a consideração de valores absolutos entre dividendos totais pagos e valor da empresa, que podem favorecer análises limitadas e incompletas. Esta característica é observada, por exemplo, nos estudos de Black e Scholes (1974), Naranjo et al. (1998), Fama e French (1998) e Pinkowitz et al. (2006). O efeito da presença de clientelas favoráveis e contrárias aos dividendos não são captados neste tipo de análise (Kim et al., 2016). As implicações das preferências dos investidores com relação aos dividendos tendem a afetar os extremos da amostra, ou seja, empresas que não distribuem dividendos ou aquelas que distribuem parcelas generosas de lucros aos acionistas.

Diante do exposto, percebe-se que a relação entre os dividendos e os valores das empresas é comumente analisada por meio de procedimentos estatísticos voltados à média das amostras, fato que não é diferente nos estudos sobre o mercado brasileiro. Com os resultados desta literatura já realizada, não se projetam estimações sobre valores dos extremos pesquisados, o que limita o poder explicativo das análises. Dado o preconizado por Miller e Modigliani (1961) e por Modigliani e Miller (1963), de que as distribuições ou retenções de lucro afetam os valores dos títulos pela preferência por recebimento imediato por ou valorização futura das ações, é pertinente apontar a necessidade de análises mais abrangentes para se avançar no estudo da temática, promovendo novos conhecimentos do comportamento do mercado brasileiro, no tangente à volatilidade de preços das ações, frente à distribuição de dividendos.

Considerando este cenário, Kim et al. (2016) encontraram uma relação em "Formato J" no mercado norte-americano e em outras 12 economias estudadas (exceção feita ao México). Com a divisão da amostra em um grupo de empresas não pagadoras de dividendos (DIVO) e cinco grupos de empresas pagadoras de dividendos, proporcionais aos dividendos pagos (de DIV1 a DIV5), este "Formato J" foi caracterizado pelo maior valor (obtido pelo $q$ de Tobin) da mediana do grupo das empresas não pagadoras de dividendos (DIVO) quando comparadas com $\circ$ grupo das pagadoras de menores parcelas de dividendos (DIVI), e do crescimento dos valores das medianas dos grupos paulatinamente ao de maiores distribuidoras de lucros. A investigação de Kim et al. (2016) permitiu demonstrar o efeito das clientelas de dividendos, conforme preconizado por Miller e Modigliani (1961) e por Black (1976).

Em função da situação detectada e descrita, a pergunta que surge é: a relação entre a segmentação dos dividendos distribuídos e o valor de mercado das empresas listadas na B3 apresenta o "Formato J"? O presente estudo tem como objetivo identificar se há a existência do "Formato J" na relação entre dividendos e valor das empresas no mercado de capitais brasileiro.

A justificativa deste estudo está pautada em algumas perspectivas, sendo: sua proposta de demonstrar o comportamento da amostra de forma segmentada pela distribuição de dividendos (não considerando somente - total de dividendos). Isso demonstra que há uma tendência de relação não linear entre dividendos e valor da empresa, pois esse tipo de associação ainda é um "quebra-cabeça" na literatura - uma vez que o valor das empresas não é somente explicado diretamente (ou unicamente) pelos dividendos, mas também por características não observadas das firmas e do mercado (levando a não linearidade relacional e explicando mais claramente a volatilidade acionária esperada). Essa abordagem realizada aqui é diferente em comparação aos estudos de Galvão et al. (2019), Galvão et al. (2018), Zanon et al. (2017), Silva Júnior e Machado (2015), e Forti et al. (2015).

Sobre isso, há de se mencionar que a importância de análises dos extremos vai ao encontro às proposições de Miller e Modigliani (1961), de que as clientelas são fatores determinantes da volatilidade do valor das ações, e serão mais afetadas as empresas que distribuem altas parcelas de dividendos e aquelas que não distribuem seus lucros, os retendo para novos investimentos. Estudos de análises aos pontos centrais das amostras seriam incompletos para demonstrar estes efeitos.

Outrossim, este estudo é diferente e justificado pelas peculiaridades do mercado brasileiro, como a variação no interesse pelos dividendos em períodos de inflação e estáveis da economia, bem como a existência de assimilação informacional ainda baixa em um mercado em desenvolvimento e a melhorar na governança corporativa (Procianoy \& Verdi, 2003).

Ainda, este estudo se diferencia por propor uma 
abordagem complementar em comparação a Kim et al. (2016). Apesar do referido estudo ser considerado como base aqui, ele não foi replicado literalmente. Houve a adaptação para o contexto brasileiro, com os juros sobre capital próprio, a forma de apurar os dividendos e diferentes variáveis independentes de controle. Com isso, adiciona-se conhecimentos diferentes, pois Kim et al. (2016) fez uma modelagem similar para todos os países e pode não ter considerado as peculiaridades dos mercados acionários.

A contribuição desta pesquisa, conforme os resultados, está em indicar a não ocorrência do "Formato J" no mercado acionário brasileiro. Diferentemente de países com o mercado mais desenvolvido, incluindo informacionalmente, como o australiano, o canadense, - norte-americano e o francês (testados em Kim et al., 2016), as evidências aqui são da relevância dos dividendos, ratificando-se o interesse dos acionistas em terem mais benefícios dos lucros e o efeito clientela dos dividendos (e "Efeito Disposição"). A percepção é a de que o valor da empresa tem relação com a efetiva distribuição de dividendos (e mais alta), e não com características não observadas das firmas que poderiam manter valorações mesmo quando da não distribuição dos lucros em comparação à dividendos menores. No Brasil, normalmente, prejuízos levam a não distribuição de dividendos e não menores dividendos.

A relevância e, ou impacto social desta investigação está em trazer conhecimentos sobre a não linearidade ou singularidade do mercado brasileiro. Gestores de empresas podem perceber que os lucros distribuídos são importantes para os acionistas, principalmente os maiores valores. A não distribuição dos dividendos ainda não é "bem vista" pelo mercado, o que traz argumentos para a academia e para as empresas buscarem e proporem meios mais informativos sobre suas atividades. Acredita-se que a Contabilidade esteja propondo isso, majoritariamente com a criação de índices "não Generally Accepted Accounting Principles - GAAP" e a melhoria de demonstrações, como a de resultados.

\section{Referencial Teórico}

\subsection{Relevância dos dividendos}

A distribuição de dividendos é tema recorrente de estudos nas áreas gerenciais por sua importância na tomada de decisão (p.ex.: Black, 1976; DeAngelo et al., 2008; Kim et al., 2016). Essa deliberação está ligada à possibilidade de reflexos no valor das empresas. Duas abordagens são discordantes neste aspecto: a da relevância (Lintner, 1956; Gordon, 1963) e a da irrelevância dos dividendos (Miller \& Modigliani, 1961). Kim et al. (2016) enfatizam que, apesar dos diversos achados, essa relação permanece como um "quebra-cabeça".

Miller e Modigliani (1961) sustentaram que os dividendos são irrelevantes para o valor da empresa. Segundo os autores, uma vez que o valor dos dividendos é subtraído do valor das ações no momento da sua divulgação, ele não é suficiente para alterar o valor dela. Por outro lado, o próprio investidor pode determinar seu retorno transacionando ações de sua propriedade. Dada a ausência de tributos, Miller e Modigliani (1961) postularam que, mesmo frente a uma distribuição de $100 \%$ do lucro, o investidor poderia produzir o retorno que desejasse vendendo e comprando novos títulos (Kim et al., 2016).

Todavia, os pressupostos de Miller e Modigliani (1961) se baseiam em um cenário de mercado perfeito e de investidores racionais. Este ponto é criticado por Baker et al. (2002), para os quais a relação dos dividendos com o valor das empresas pode ser influenciada pelas imperfeições do mercado, por assimetrias informacionais, por conflitos de interesses entre gerentes e acionistas, pelos custos de transação e de flotação, e pelo comportamento irracional dos investidores. Outro fator contrário à teoria da irrelevância dos dividendos é apontado por DeAngelo e DeAngelo (2006). Para os autores, a questão principal da teoria, sobre as maiores distribuições de dividendos resultarem em ações sobrevalorizadas, não é abordada nas suas análises, pois o efeito conjunto de suas premissas é exigir $100 \%$ do pagamento do fluxo de caixa livre em cada período disponível, tornando os menores pagamentos inviáveis.

Defendendo a relevância dos dividendos no valor das empresas, Lintner (1956) afirmou que a política de dividendos estável é a preferência dos gestores. Para o autor, os dividendos teriam um crescimento proporcional ao lucro sustentado e os gestores evitariam cortar dividendos, só o fazendo quando o resultado negativo é persistente, trazendo-se um caráter informacional ao dividendo. Nesse sentido, Beaver et al. (1997) e Ross et al. (2008) discorreram que um dos papeis dos dividendos é transmitir informações sobre a situação atual e a expectativa futura por parte das empresas, dado que a expectativa de dividendos é associada aos fluxos projetados futuros.

Por outro lado, o risco presente em transações pode 
motivar investidores a exigir o retorno sobre o capital investido o quanto antes. Dessa forma, a importância da distribuição do caixa livre se dá pela insegurança dos investidores com relação ao futuro. Portanto, os acionistas preferirão os ganhos em dividendos. Este é o cerne da teoria da preferência dos dividendos pelos acionistas, proposta por Gordon (1963). Aliados a ela, os postulados de Lintner (1956) formam a Teoria do "Pássaro na Mão".

Outros estudos apontaram motivos para a preferência dos acionistas pelo recebimento dos dividendos. Shefrin e Statman (1984) creditaram a preferência pelos dividendos à ingenuidade dos investidores, trabalhando uma teoria comportamental conhecida como "Efeito Disposição". A diferença fundamental entre os pressupostos de Lintner (1956) e Gordon (1963) e os de Shefrin e Statman (1984) reside na finalidade da exigência dos dividendos uma vez que, para os primeiros, o investidor teme as incertezas futuras enquanto os últimos advogam o desejo pelo consumo dos recursos (Bezawada \& Tati, 2017). Ainda, Baker e Weigand (2015) apontaram os fatores para se defender a relevância dos dividendos: (i) o efeito clientela; (ii) a teoria de Lintner (1956) e Gordon (1963); (iii) a hipótese do conteúdo informacional; (iv) as preferências tributárias; (v) os custos de agência; (vi) a Teoria do Ciclo de Vida e (vii) a Teoria do Catering.

Ainda que suas preposições tenham sido em desfavor da relação entre dividendos e valor das empresas, Miller e Modigliani (1961) se atentaram para o efeito clientela, ou seja, para a parcela de investidores que possui preferência pelo recebimento dos dividendos. A predileção dos investidores por maiores proporções de dividendos, independente do motivo da preferência, é levada em conta pelos gerentes (Baker \& Wurgler, 2004). Entretanto, a dificuldade em se conhecer a clientela parece ser tamanha que Black (1976) alegou ser virtualmente impossível se conhecer com segurança qual tipo de clientela é imperativa.

As implicações das preferências dos investidores com relação aos dividendos tendem a afetar os extremos da amostra, ou seja, empresas que não distribuem dividendos ou aquelas que distribuem parcelas generosas de lucros aos acionistas. Considerando este cenário, Kim et al. (2016) propuseram uma divisão da amostra de acordo com o dividendo distribuído (onde as empresas não pagadoras de dividendos foram agrupadas no grupo DIVO e as demais empresas, em ordem crescente de distribuição de lucros, agrupadas nos grupos DIV1 a DIV5) evidenciando uma relação em "Formato J" no mercado norte-americano e em outras 12 economias estudadas (exceção feita ao
México). Essa ideia está representada na Figura 1.

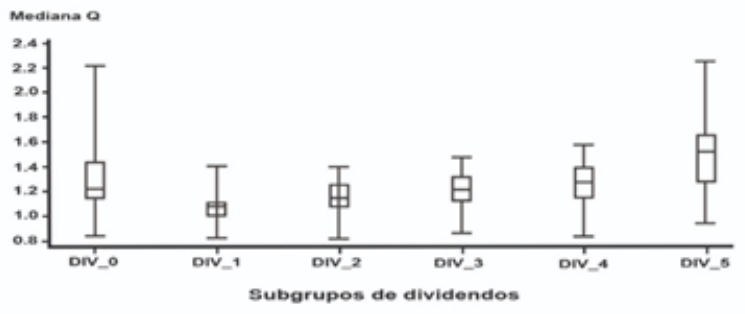

Figura 1. Relação encontrada por Kim et al. (2016) analisando os dividendos e o valor das empresas norte-americanas (representado pelo q de Tobin) entre 1962 e 2012.

Esse "Formato J" foi caracterizado pelo maior valor da mediana do grupo das empresas DIVO (obtido pelo q de Tobin) quando comparadas com o grupo das pagadoras de menores parcelas de dividendos (DIV1), e do aumento dos valores das medianas dos grupos paulatinamente ao de maiores distribuidoras de lucros. A investigação de Kim et al. (2016), por meio da Tabela 7 do referido artigo, p. 34, permitiu demonstrar o efeito das clientelas de dividendos, conforme preconizado por Miller e Modigliani (1961) e por Black (1976).

Pela ótica das empresas, Miller e Modigliani (1961) indicaram sobre a minimização dos custos de transação, enquanto Dhaliwal et al. (1999) e Moser e Puckett (2009) postularam sobre a dedução fiscal por parte das empresas como um fator para a decisão do pagamento de dividendos. Já Ehrhardt e Brigham (2014) e Fama e French (2001) apontaram para o ciclo de vida e o tamanho das empresas como fator para a distribuição de dividendos. Ehrhardt e Brigham (2014) afirmaram que empresas maduras e com possibilidades limitadas de crescimento tendem a distribuir grandes parcelas de seus fluxos de caixa aos acionistas, como dividendos ou como recompra de ações. Pelo contrário, empresas que apresentam crescimento rápido optam pela retenção e reinvestimento do caixa disponível em novos projetos, conforme explanaram Fama e French (2001). Nesse sentido, Fama e French (2001) reportam uma queda no número de empresas que distribuem dividendos, no mercado americano, devido ao crescente número de empresas pequenas, com baixa lucratividade e com boas oportunidades de crescimento.

Assim como os acionistas, na proposição de Lintner, também os investidores institucionais apresentam a percepção de que um aumento nos dividendos é refletido positivamente nas ações. Contudo, eles possuem uma predileção pelos ganhos de capital aos dividendos 
como remuneração (Farrelly \& Baker, 1989). Todavia, esta predileção pode ser modificada, por exemplo, com alterações na política de tributação dos dividendos e de ganhos da capital (Ehrhardt \& Brigham, 2014).

A distribuição dos dividendos, no Brasil, possui algumas particularidades que a diferencia dos mercados principais. A não incidência tributária nos dividendos, a figura dos Juros Sobre Capital Próprio, a alta concentração de ações e a participação do governo no mercado são algumas dessas diferenciações. Além disso, o mercado possui baixo número de empresas negociando, ainda há a existência de dois tipos de ações (dual class) em algumas empresas e o mercado apresenta baixa liquidez. Ademais, há a determinação de uma proporção mínima do lucro líquido a ser distribuído, quando não há pactuação no Estatuto da empresa, e que aumentos de endividamentos geram diminuição de pagamentos de dividendos no presente com expectativa de reversão no futuro (Forti et al., 2015; Camargos et al., 2012; Loss \& Sarlo Neto, 2006).

\subsection{Teoria de Agência: Dividendos e Valor da Empresa (Ação)}

Uma das formas propostas para reduzir os custos de agência é a concentração da propriedade, que promoveria uma maior capacidade de monitoramento por parte dos grandes investidores frente os gestores (Jensen \& Meckling, 1976; Shleifer \& Vishny, 1986). Isto seria refletido no comportamento do mercado, que precificaria melhor as empresas de maior concentração acionária, pois haveria menores gastos de monitoramento (Marques et al., 2015). Lloyd et al. (1985) também postularam os benefícios da concentração de propriedade. Os autores argumentaram que a dispersão de propriedade dificulta o monitoramento por parte dos insiders.

A relação entre a Teoria de Agência e os dividendos se dá pela diminuição de recursos nas mãos dos Agentes (Jensen \& Meckling, 1976; Gugler \& Yurtoglu, 2003; Rodrigues \& Ambrozini, 2016). Isto eleva o prêmio por ações das empresas que distribuem maiores proporções de dividendos (Jensen \& Meckling, 1976; Ehrhardt \& Brigham, 2014; Rodrigues \& Ambrozini, 2016).

Em uma situação de investimento, a empresa necessitaria recorrer ao mercado para realizar novos aportes de capitais. Isto inibiria ações oportunistas dos agentes, dada a maior capacidade avaliativa por parte dos acionistas (Baker \& Powell, 1999; Easterbrook, 1984; Harada \& Nguyen, 2006; Hardin \& Hill, 2008; Holder et al., 1998; Lloyd et al., 1985). Assim, a maior distribuição de lucros aos acionistas promoveria uma melhor avaliação das empresas pela maior facilidade de controle dos agentes por parte dos acionistas. Porém, a escassez de recursos no longo prazo e o baixo valor das ações negociadas podem indicar retenção de lucros como escolha pelos gestores (Vancin \& Procianoy, 2016).

\subsection{Hipóteses do estudo}

Kim et al. (2016) concluíram que o mercado norteamericano, além de outras 12 economias analisadas (com exceção do México), tendem ao "Formato J" na distribuição de dividendos. No Brasil, o intuito é que isso também ocorra. No entanto, o país apresenta um mercado caracterizado por ser formado por poucas empresas, baixa liquidez de ações, comportamento especulativo e expressiva participação estatal em empresas significativas, bem como a presença de características legais como - dividendo mínimo obrigatório e a não tributação sobre eles, $\circ$ que $\circ$ difere dos mercados principais mundiais (Camargos et al. 2012). As grandes empresas possuem maior facilidade de contração de dívidas para realização de investimentos em oportunidades de crescimento ou diversificação, realizando o trade-off de não pagamento de dividendos em vista de uma maior valorização de ações, o que é um fator de promoção das empresas não pagadoras de dividendos (Kim, et al, 2016; Miller \& Modigliani, 1961). Contudo, no Brasil, há também maior volatilidade e, portanto, maior risco, oriundos, por exemplo, do aumento do custo financeiro do endividamento (Vancin \& Procianoy, 2016), o que resultaria numa aversão às empresas que não distribuem fluxo de caixa aos acionistas (Shefrin \& Statman, 1984). Logo, tem-se a primeira hipótese deste estudo.

$\mathrm{H}_{1}$ : $\mathrm{O}$ mercado brasileiro apresenta uma relação entre dividendos e valor de empresas similar aos mercados internacionais, caracterizando uma relação "Formato J".

Apesar de se perceber na literatura que a relação dividendos e valor é um "quebra-cabeça", no cenário brasileiro, pode-se afirmar que "a distribuição de lucros aos acionistas impacta a precificação da empresa realizada pelo mercado, o que permite a consolidação da significância da política de dividendos na gestão das instituições financeiras atuantes no mercado de capitais interno" (Silva \& Dantas, 2015, p. 53). Assim, a expectativa desta pesquisa, de acordo com os achados na literatura internacional, é de que o pagamento de dividendos seja visto pelos investidores como um indicador da expectativa sobre o futuro da empresa, gerando mais valor (Lintner, 1956). 
Além disso, é uma garantia de remuneração do capital investido, diminuindo o risco promovido pela incerteza do mercado (Shefrin \& Statman, 1984). Os estudos sobre a influência dos dividendos no valor das empresas no país, apesar de alguns resultados discordantes (p.e.: Zanon et al., 2017; e Silva Júnior \& Machado, 2015) e de serem ainda incipientes quando comparados aos mercados desenvolvidos (Martins \& Famá, 2012), têm em comum o fundamento da relação lucros distribuídos e valoração da empresa. Assim, a hipótese é apresentada:

$\mathrm{H}_{2}$ : Os dividendos são diretamente relacionados com 0 valor das empresas do mercado brasileiro.

\section{Procedimentos Metodológicos}

Com vistas ao objetivo de identificar se há a existência do "Formato J" na relação entre dividendos e valor das empresas no mercado de capitais brasileiro (Kim et al., 2016), utilizou-se das empresas ativas listadas na B3, no período de 1996 a 2018. A escolha por este período se deu pela não incidência de tributação nos dividendos, determinada pela Lei 9.249 (Brasil, 1995) e pela estabilidade econômica após a implementação do Plano Real (Correia \& Amaral, 2002). Foram utilizadas 3.556 observações (Tabela 1).

Os dados foram obtidos por meio de coleta no banco

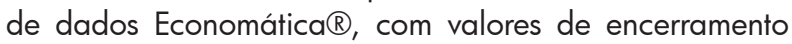
anual. Foram coletadas informações de valor de mercado, ativo circulante, ativo total, caixa e disponibilidades, estoques, passivo circulante e não circulante, dividendos pagos, JSCP, lucro operacional/EBIT, Reservas de Lucro, Receita Líquida de Vendas, Retorno sobre os ativos (ROA), grau de alavancagem financeira e operacional, EBITDA e composição acionária.

Tabela 1. Composição dos dados do estudo

\begin{tabular}{|c|c|c|c|}
\hline \multicolumn{4}{|c|}{ Painel A - Composição da amostra } \\
\hline Operacionalizações & \multicolumn{2}{|c|}{$\begin{array}{l}\text { Títulos acionários representativos } \\
\text { das empresas }\end{array}$} & $\begin{array}{l}\text { Observações } \\
(\mathbf{N})\end{array}$ \\
\hline População Inicial & \multicolumn{2}{|c|}{539} & 7.645 \\
\hline (-) Ações do setor financeiro & \multicolumn{2}{|c|}{122} & 1.536 \\
\hline (-) Ações dual class & \multicolumn{2}{|c|}{146} & 2.376 \\
\hline (-) Exclusões & \multicolumn{2}{|c|}{ - } & 177 \\
\hline ( $=$ Amostra & \multicolumn{2}{|c|}{271} & 3.556 \\
\hline \multicolumn{4}{|c|}{ Painel B - Amostra por setores } \\
\hline Setor Economática@ & $\begin{array}{l}\text { Número de } \\
\text { Empresas }\end{array}$ & Observações & $\begin{array}{l}\text { Participação } \\
\text { de Observa- } \\
\text { ções (\%) }\end{array}$ \\
\hline Agro e Pesca & 5 & 42 & 1,18 \\
\hline Alimentos e Bebidas & 12 & 154 & 4,33 \\
\hline Comércio & 18 & 231 & 6,50 \\
\hline
\end{tabular}

\begin{tabular}{|c|c|c|c|}
\hline Construção & 23 & 254 & 7,14 \\
\hline Eletroeletrônicos & 4 & 47 & 1,32 \\
\hline Energia Elétrica & 40 & 620 & 17,44 \\
\hline Máquinas Indust. & 6 & 88 & 2,48 \\
\hline Mineração & 4 & 43 & 1,21 \\
\hline Minerais não Met. & 3 & 48 & 1,35 \\
\hline Outros & 54 & 552 & 15,50 \\
\hline Papel e Celulose & 4 & 75 & 2,11 \\
\hline Petróleo e Gás & 10 & 122 & 3,43 \\
\hline Química & 10 & 126 & 3,54 \\
\hline Siderug. \& Metalurg. & 18 & 328 & 9,23 \\
\hline Software e Dados & 5 & 24 & 0,68 \\
\hline Telecomunicações & 4 & 88 & 2,48 \\
\hline Têxtil & 19 & 294 & 8,27 \\
\hline Transp. \& Serviço & 18 & 136 & 3,83 \\
\hline Veículos e Peças & 14 & 284 & 7,99 \\
\hline Totais & $\mathbf{2 7 1}$ & $\mathbf{3 . 5 5 6}$ & $\mathbf{1 0 0 , 0 0}$ \\
\hline
\end{tabular}

Nota. Fonte: Elaborado pelos autores.

Ainda se menciona que foram obtidos dados de 539 títulos de ações preferenciais ou ordinárias, que constituem a população deste estudo. Destas, foram excluídas as ações emitidas por empresas categorizadas como bancos, financeiras, holdings e assemelhadas devido às suas particularidades estatutárias, regulatórias, tributárias, operacionais e de distribuição de resultados líquidos aos acionistas.

Ademais, utilizou-se de apenas uma ação por empresa, sendo selecionadas as de maior volume de negociações dentro de cada período anual, com a finalidade de se evitar a duplicidade dos dados. Assim, 146 ações, com um total de 2.376 observações foram excluídas. Por fim, foram excluídas as observações que (i) não apresentaram valor de mercado e (ii) não dispunham do valor de dividendo distribuído. Essa exclusão englobou 177 observações. Assim, a amostra foi constituída por 271 ações de 271 empresas, negociadas na Bolsa ao longo do período estudado, e por 3.556 observações.

Com o exposto, o modelo principal utilizado é apresentado:

$q_{i t}=\beta_{1} D I V_{i t}+\beta_{2} E B I T D A_{i t}+\beta_{3} R E_{\text {it }}+\beta_{4} C V_{i t}+\beta_{5} R O A_{i t}+\beta_{6}$ $T A_{i t}+\beta_{7} C A S H_{i t}+\beta_{8} I N V_{i t}+\beta_{9}$ AlaFIN $_{i t}+\beta_{10} E S T_{i t}+\beta_{11} D I V x_{i t}$ $+a+e_{i t}$ (1)

Em que: $\mathrm{i}$ - empresas; $\dagger$ - anos; $a_{\mathrm{i}}$ é o termo específico invariante da regressão; $e_{\text {it }}$ é o erro residual regressional. $\mathrm{Na}$ regressão foi utilizada a técnica de dados em painel por meio software Stata.

As variáveis dependente e independente utilizadas (e seus 
relações) neste estudo são descritas na Tabela 2.

Tabela 2. Variáveis utilizadas nesta pesquisa, de 1996 a 2018.

\begin{tabular}{|c|c|c|c|c|}
\hline \multicolumn{5}{|c|}{ Painel A - Variável Dependente } \\
\hline Variáveis & Descrição & Fórmulas & $\begin{array}{l}\text { Relação } \\
\text { Esperada }\end{array}$ & $\begin{array}{c}\text { Funda- } \\
\text { mentação } \\
\text { Teórica }\end{array}$ \\
\hline $\begin{array}{l}9 \mathrm{de} \\
\text { Tobin }\end{array}$ & $\begin{array}{l}\text { Valor das } \\
\text { empresas }\end{array}$ & $q=V M^{a}+V D^{b} / A T^{c}$ & - & $\begin{array}{l}\text { Kim et al. } \\
(2016) ; \\
\text { Grando et } \\
\text { al. }(2016)\end{array}$ \\
\hline \multicolumn{5}{|c|}{ Painel B - Variáveis Independente e de Controle } \\
\hline DIV & $\begin{array}{l}\text { Lucro } \\
\text { distribuído }\end{array}$ & $\begin{array}{c}\mathrm{DIV}_{\mathrm{t}}=(\text { Dividendos } \\
\mathrm{AT}_{\mathrm{t}}+\mathrm{JSCP}\end{array}$ & Positiva & $\begin{array}{l}\text { Kim et al. } \\
(2016)\end{array}$ \\
\hline EBITDA & $\begin{array}{l}\text { Volatilidade } \\
\text { do Lucro } \\
\text { Operacional }\end{array}$ & EBITDA $_{t}-$ EBITDA $_{t-1} / A_{t}$ & Positiva & . \\
\hline RETE & $\begin{array}{l}\text { Lucros } \\
\text { Recidos }\end{array}$ & Res.Lucro, - Res.Lucro ${ }_{t-1} / \mathrm{AT}_{t}$ & Negativa & $\begin{array}{l}\text { Kim et al. } \\
(2016)^{*}\end{array}$ \\
\hline $\mathrm{CV}$ & $\begin{array}{l}\text { Crescimento } \\
\text { de Vendas }\end{array}$ & $\begin{array}{l}\text { Rec.Liq.Vendas }- \text { Rec.liq. } \\
\text { Vendas } s_{t-1} / A T_{t}\end{array}$ & Positiva & $\begin{array}{l}\text { Kim et al. } \\
(2016)\end{array}$ \\
\hline ROA & $\begin{array}{l}\text { Retorno } \\
\text { sobre o ativo }\end{array}$ & Índice Economática & Positiva & $\begin{array}{l}\text { Kim et al. } \\
\text { (2016); } \\
\text { Fama e } \\
\text { French } \\
(2001)\end{array}$ \\
\hline TA & Ativo total & $\log _{10} A T_{t}$ & Positiva & $\begin{array}{l}\text { Kim et al. } \\
\text { (2016); } \\
\text { Fama e } \\
\text { French } \\
(2001)\end{array}$ \\
\hline CASH & $\begin{array}{c}\text { Caixa } \\
\text { disponivel }\end{array}$ & Caixa e disponível, $/ A T_{t}$ & Negativa & $\begin{array}{l}\text { Kim et al. } \\
(2016) ; \\
\text { Fama e } \\
\text { French } \\
(2001)\end{array}$ \\
\hline INV & Investimento & $\mathbb{I N V}=A T_{t}-A T_{t-1} / A T_{t}$ & Negativa & $\begin{array}{c}\text { Miller e } \\
\text { Modigliani } \\
\text { (1961); } \\
\text { Fama e } \\
\text { French } \\
\text { (2001) }\end{array}$ \\
\hline AlaFIN & $\begin{array}{l}\text { Alavancagem } \\
\text { financeira }\end{array}$ & Índice Economática & Negativa & $\begin{array}{l}\text { Kim et al. } \\
(2016)\end{array}$ \\
\hline EST & $\begin{array}{c}\text { Total de } \\
\text { estoques } \\
\text { declarado } \\
\text { nos informes }\end{array}$ & Estoque $_{t} / \mathrm{AT}_{+}$ & Negativa & - \\
\hline DIVx & $\begin{array}{l}\text { Classificacãão } \\
\text { por nível de } \\
\text { DIV }\end{array}$ & $\begin{array}{l}\text { Dummy: } 1 \text { para o grupo } \\
\text { DIV analisado e } 0 \text { para } \\
\text { demais grupos }\end{array}$ & - & $\begin{array}{l}\text { Kim et al. } \\
(2016)\end{array}$ \\
\hline
\end{tabular}

Nota. Fonte: Elaborado pelos autores. *Usado com adaptações na fórmula. aVM é o valor de mercado das ações da empresa. ${ }^{b} \mathrm{VD}$ é o valor das dívidas da empresa. ${ }^{`} A T=$ ativo contábil total da empresa.

O índice q permite que o valor da empresa seja representado por uma grandeza comparável entre as diferentes firmas, reduzindo as distorções causadas pelo uso de valores monetários, por exemplo. O cálculo do índice q foi realizado para cada empresa em cada ano observado, conforme Kammler e Alves (2007).

A fórmula DIV descreve o cálculo utilizado para dimensionar as empresas de acordo com sua distribuição de lucros aos acionistas (Cf. Kim et al., 2016). A divisão pelo ativo total visa eliminar as disparidades do uso de valores nominais. É importante destacar que, para o presente trabalho, a distribuição dos lucros aos acionistas, tanto por meio de dividendos quanto por meio de JSCP foi nomeada como "dividendos".

Na variável $D I V$, os resultados foram categorizados em função da distribuição ou não de lucros, anualizados. Os valores das empresas não pagadoras de dividendos da amostra foram agrupados sob a denominação DIVO. O restante, composto de empresas distribuidoras de lucros, foi dividido em quintis (Kim et al., 2016). Para tal, usou-se uma classificação crescente, ordenados pelo valor DIVt encontrado. Deste modo, empresas que pagaram menores parcelas de dividendos foram agrupadas no quintil inferior, classificadas como DIVI. As empresas que distribuíram maiores proporções de lucros aos acionistas são classificadas como DIV5, ocupando o quintil superior. Grupos DIV2, DIV3 e DIV4 são, igualmente, proporcionais aos pagamentos. Com esses dados foi possível conhecer a o formato da distribuição de dividendos no valor das empresas.

\section{Resultados e Discussão}

Em primeiro lugar, destaca-se a estatística descritiva, através da qual se evidenciou o formato da relação dividendos $x$ valor das empresas no mercado brasileiro (Tabela 3).

Tabela 3. Estatística descritiva das variáveis independente e dependente, dos Grupos DIVx

\begin{tabular}{|c|c|c|c|c|c|c|c|}
\hline DIVx & Estatistica & q de Tobin & DIV & EBITDA & RETE & CV & ROA \\
\hline \multirow{6}{*}{ DIVO } & Mínimo & 0,0545 & & $-1,2077$ & $-0,1260$ & $-1,2706$ & - 221,5088 \\
\hline & Média & 0,8838 & & 0,0056 & $\cdot 0,0010$ & 0,0148 & $-11,8706$ \\
\hline & Mediana & 0,5903 & & 0,0047 & . & 0,0181 & $-2,9951$ \\
\hline & $0.25-0.75$ & 0,5397 & & 0,0919 & - & 0,1231 & 14,2997 \\
\hline & D. Padrão & 1,2023 & & 0,2658 & 0,0272 & 0,2177 & 32,9196 \\
\hline & Máximo & 9,2604 & & 1,1544 & 0,1380 & 0,6280 & 36,3095 \\
\hline \multirow{6}{*}{ DIV1 } & Mínimo & 0,1341 & 0,0000 & $\cdot 0,1792$ & $\cdot 0,1286$ & $\cdot 0,3033$ & $\cdot 21,1731$ \\
\hline & Média & 0,7509 & 0,0033 & 0,0089 & 0,0016 & 0,0644 & 0,3823 \\
\hline & Mediana & 0,6310 & 0,0029 & 0,0099 & 0,0006 & 0,0474 & 1,0472 \\
\hline & $0.25-0.75$ & 0,4312 & 0,0044 & 0,0497 & 0,0193 & 0,1275 & 3,7825 \\
\hline & D. Padrão & 0,5579 & 0,0027 & 0,0589 & 0,0311 & 0,1407 & 5,0417 \\
\hline & Máximo & 4,1443 & 0,0114 & 0,1976 & 0,0959 & 0,6681 & 16,8623 \\
\hline \multirow{6}{*}{ DIV2 } & Mínimo & 0,1885 & 0,0034 & $-0,1410$ & $.0,0996$ & $-0,3447$ & $-11,1990$ \\
\hline & Média & 0,8828 & 0,0113 & 0,0128 & 0,0161 & 0,0817 & 3,6121 \\
\hline & Mediana & 0,7401 & 0,0107 & 0,0120 & 0,0164 & 0,0638 & 3,5600 \\
\hline & $0.25-0.75$ & 0,5188 & 0,0055 & 0,0447 & 0,0323 & 0,1360 & 3,7828 \\
\hline & D. Padrão & 0,5367 & 0,0044 & 0,0500 & 0,0367 & 0,1404 & 3,8069 \\
\hline & Máximo & 3,0659 & 0,0255 & 0,1989 & 0,1332 & 0,5180 & 13,8863 \\
\hline
\end{tabular}




\begin{tabular}{|c|c|c|c|c|c|c|c|}
\hline \multirow{6}{*}{ DIV3 } & Mínimo & 0,2302 & 0,0098 & $-0,2299$ & $\cdot 0,1110$ & $\cdot 0,3158$ & $\cdot 14,5911$ \\
\hline & Média & 0,9799 & 0,0205 & 0,0113 & 0,0212 & 0,0830 & 5,4928 \\
\hline & Mediana & 0,8207 & 0,0194 & 0,0151 & 0,0208 & 0,0610 & 5,6031 \\
\hline & $0.25-0.75$ & 0,5725 & 0,0073 & 0,0533 & 0,0434 & 0,1333 & 4,6532 \\
\hline & D. Padrão & 0,5709 & 0,0062 & 0,0566 & 0,0463 & 0,1496 & 4,6582 \\
\hline & Máximo & 3,2933 & 0,0394 & 0,1540 & 0,2141 & 0,6700 & 18,1804 \\
\hline \multirow{6}{*}{ DIV4 } & Mínimo & 0,2299 & 0,0192 & $-0,1648$ & $-0,1410$ & $\cdot 0,3666$ & $\cdot 10,3817$ \\
\hline & Média & 1,2347 & 0,0358 & 0,0151 & 0,0243 & 0,0858 & 7,6509 \\
\hline & Mediana & 1,0181 & 0,0339 & 0,0168 & 0,0233 & 0,0649 & 7,2964 \\
\hline & $0.25-0.75$ & 0,8142 & 0,0135 & 0,0463 & 0,0504 & 0,1287 & 5,9545 \\
\hline & D. Padrão & 0,8108 & 0,0105 & 0,0520 & 0,0481 & 0,1435 & 5,0025 \\
\hline & Máximo & 4,7768 & 0,0648 & 0,1597 & 0,1568 & 0,6598 & 19,9896 \\
\hline \multirow{6}{*}{ DIV5 } & Mínimo & 0,3111 & 0,0308 & $-0,2845$ & $-0,2123$ & $-0,3950$ & $-1,4071$ \\
\hline & Média & 1,6387 & 0,0962 & 0,0169 & 0,0161 & 0,0818 & 11,4203 \\
\hline & Mediana & 1,2804 & 0,0800 & 0,0182 & 0,0077 & 0,0608 & 10,5596 \\
\hline & $0.25-0.75$ & 1,1155 & 0,0577 & 0,0576 & 0,0516 & 0,1110 & 7,0497 \\
\hline & D. Padrão & 1,1430 & 0,0648 & 0,0693 & 0,0643 & 0,1377 & 5,8518 \\
\hline & Máximo & 6,0801 & 0,4878 & 0,2154 & 0,2806 & 0,6144 & 29,6735 \\
\hline DIV $x$ & Estatistica & TA & CASH & INV & AlafiN & EST & \\
\hline \multirow{6}{*}{ DIVO } & Mínimo & 3,9341 & & $-3,5821$ & - 180,4423 & . & \\
\hline & Média & 5,8250 & 0,0620 & $\cdot 0,0269$ & 3,3318 & 0,0924 & \\
\hline & Mediana & 5,8497 & 0,0245 & 0,0337 & 0,7668 & 0,0678 & \\
\hline & $0.25-0.75$ & 1,0654 & 0,0683 & 0,1883 & 5,6622 & 0,1414 & \\
\hline & D. Padrão & 0,7542 & 0,1119 & 0,4713 & 39,5382 & 0,0975 & \\
\hline & Máximo & 7,3092 & 0,7412 & 0,7238 & 239,6431 & 0,4053 & \\
\hline \multirow{6}{*}{ DIV1 } & Mínimo & 4,6957 & 0,0002 & $\cdot 0,3825$ & $.51,6662$ & - & \\
\hline & Média & 6,4530 & 0,0754 & 0,0982 & 1,7315 & 0,1049 & \\
\hline & Mediana & 6,4727 & 0,0599 & 0,0699 & 1,0675 & 0,0951 & \\
\hline & $0.25-0.75$ & 1,1162 & 0,0835 & 0,1578 & 1,7823 & 0,1660 & \\
\hline & D. Padrão & 0,7990 & 0,0663 & 0,1775 & 15,7443 & 0,0976 & \\
\hline & Máximo & 8,2380 & 0,3016 & 0,7012 & 135,4344 & 0,3674 & \\
\hline \multirow{6}{*}{ DIV2 } & Mínimo & 4,8449 & 0,0011 & $-0,3603$ & $\cdot 13,4053$ & & \\
\hline & Média & 6,4440 & 0,0772 & 0,1236 & 2,6626 & 0,1098 & \\
\hline & Mediana & 6,4437 & 0,0563 & 0,0880 & 1,6135 & 0,1029 & \\
\hline & $0.25-0.75$ & 1,1146 & 0,0754 & 0,1558 & 1,2527 & 0,1654 & \\
\hline & D. Padrão & 0,7363 & 0,0653 & 0,1776 & 8,2222 & 0,1044 & \\
\hline & Máximo & 8,1400 & 0,2936 & 0,7308 & 68,1748 & 0,4202 & \\
\hline \multirow{6}{*}{ DIV3 } & Mínimo & 4,7875 & 0,0009 & $-0,2666$ & $\cdot 10,1463$ & . & \\
\hline & Média & 6,4402 & 0,0874 & 0,1091 & 1,8954 & 0,1103 & \\
\hline & Mediana & 6,4363 & 0,0637 & 0,0891 & 1,6996 & 0,0956 & \\
\hline & $0.25-0.75$ & 1,0597 & 0,0988 & 0,1439 & 0,9946 & 0,1667 & \\
\hline & D. Padrão & 0,7433 & 0,0729 & 0,1488 & 2,4949 & 0,1090 & \\
\hline & Máximo & 8,4656 & 0,3426 & 0,6476 & 15,4050 & 0,4282 & \\
\hline \multirow{6}{*}{ DIV4 } & Mínimo & 4,7397 & 0,0009 & $-0,3214$ & $\cdot 6,3088$ & & \\
\hline & Média & 6,4312 & 0,1017 & 0,1052 & 1,8269 & 0,0914 & \\
\hline & Mediana & 6,5057 & 0,0785 & 0,0954 & 1,7435 & 0,0729 & \\
\hline & $0.25-0.75$ & 1,2021 & 0,1141 & 0,1250 & 0,9788 & 0,1414 & \\
\hline & D. Padrão & 0,8001 & 0,0877 & 0,1313 & 1,8573 & 0,0988 & \\
\hline & Máximo & 8,4264 & 0,4121 & 0,5416 & 10,8507 & 0,4114 & \\
\hline
\end{tabular}

\begin{tabular}{|c|c|c|c|c|c|c|}
\hline \multirow{4}{*}{ DIV5 } & Mínimo & 4,5065 & 0,0004 & $-0,5991$ & $-5,6650$ &. \\
\cline { 2 - 7 } & Média & 6,3514 & 0,1029 & 0,0710 & 1,8337 & 0,0652 \\
\cline { 2 - 7 } & Mediana & 6,4250 & 0,0757 & 0,0684 & 1,7940 & 0,0116 \\
\cline { 2 - 7 } & $0.25-0.75$ & 0,8998 & 0,1135 & 0,1486 & 0,8968 & 0,1183 \\
\cline { 2 - 7 } & D. Padrão & 0,7285 & 0,1132 & 0,1575 & 1,2589 & 0,0842 \\
\cline { 2 - 7 } & Máximo & 7,8760 & 0,7249 & 0,6951 & 5,0405 & 0,3653 \\
\hline
\end{tabular}

Nota. Fonte: Elaborado pelos autores.

Do total da amostra analisada, em $31,16 \%$ dos eventos (1.108 observações) não foi percebida a distribuição de dividendos. Isto revela que há uma parcela significativa de empresas negociando, cujo valor de mercado não pode ser explicado por influência das teorias sobre dividendos. Além disso, torna-se o DIVO ○ maior dos grupos analisados, em números de observações. Os grupos entre DIV1 e DIV4 são formados por 490 observações cada, enquanto o grupo DIV5 possui 488 observações.

A análise das medianas de $q$ dos grupos revela que 0 valor das empresas brasileiras é inferior ao valor $q$ das empresas americanas e das empresas dos demais países do estudo de Kim et al. (2016). Parece razoável inferir que particularidades do mercado brasileiro como a presença do governo (regulador de mercado) como acionista em empresas significativas (Carvalho \& Ribeiro, 2019), alta concentração de ações em posse do majoritário (Vancin \& Procianoy, 2016), baixa liquidez de títulos (Nogueira et al., 2021) e sua natureza especulativa de negociação, possam ser motivadores para os baixos índices de valor observados.

A variável $R O A$ foi destacada para se caracterizar $\circ$ comportamento do mercado com relação à distribuição de dividendos. O grupo DIVO não foi composto apenas por empresas com resultados líquidos negativos ou nulos, embora os valores de interesse (média e mediana) sejam negativos. Do total de 1.108 observações, 389 eventos, ou $35,11 \%$ do grupo, apresentaram $R O A$ positivo. Este resultado é consonante com os relatos de Vancin e Procianoy (2016), sobre a retenção dos lucros no mercado brasileiro. Contudo, análise dos motivos para este cenário não é pertinente aos objetivos do presente trabalho. Para os demais grupos, notase uma variação positiva dos valores de $R O A$ com relação aos grupos $D I V x$,

Há ainda a se destacar que por meio da média e da mediana percebeu-se que os valores do $q$ de Tobin, dos estoques, das disponibilidades, das alavancagens operacionais, dos EBITDA(s), dos investimentos, dos lucros retidos, dos crescimentos das vendas, ficam maiores quanto mais as empresas distribuem dividendos - principalmente a partir de DIV3. Esse cenário pode ser explicado pelo ciclo em distribuir dividendos e obter retornos do mercado, trazendo 
mais possibilidades de recursos. Ainda, os próprios gestores buscam manter adequadas estruturas empresariais para interesses de maiores remunerações variáveis.

Quando analisado o comportamento dos grupos, os valores de mediana de q são maiores à medida que se avançam nos grupos. Ou seja, o grupo DIVO possui o menor valor mediano de empresas, enquanto o grupo DIV5 o maior valor. Além disso, DIV5 também é o grupo que apresentou maior valor q (média ou mediana), maior intervalo interquartílico e maior desvio padrão para esta variável, dentre os grupos estudados. Os grupos extremos (DIVO e DIV5) apresentaram as maiores dispersões no valor de q, como observado pelos valores de desvio padrão. Este comportamento, para o grupo de não pagadores de dividendos, pode ser atribuído ao maior número de observações contidas. Para o grupo DIV5, este comportamento pode ser explicado pela política de manutenção da forma de pagamento e dos níveis de payout, adotada no mercado brasileiro (Galvão et al., 2018), o que passa a ser interpretado pelo investidor como uma remuneração constante sobre o capital investido, diminuindo o risco do investimento, além da sinalização ao mercado da projeção futura da empresa (Beaver et al, 1997; Gordon, 1963; Lintner, 1956; Ross et al., 2008). Ainda, infere-se que a presença e manutenção da distribuição generosa de dividendos sobrepujaria a análise de outras variáveis por parte dos investidores, provocando o comportamento analisado de maior dispersão dos valores de q no Grupo DIV5.

A análise das medianas dos grupos $D I V x$ não caracteriza - formato da distribuição de dividendos no Brasil como "Formato J" (Figura 2). Por outro lado, o comportamento é similar ao descrito no México, com o grupo de empresas que não distribuem dividendos (DIVO) sendo pior avaliado, pela análise da mediana, do que o grupo de empresas com a menor distribuição (DIV1). Ambos mercados possuem similaridades: são mercados latinos, de países em desenvolvimento, com baixa representatividade de empresas negociando no mercado aberto, são mercados especulativos e não possuem taxação sobre dividendos. Dessas características, a não taxação dos dividendos ocorre em outros seis países os quais reportaram maior valor para o grupo DIVO em comparação ao DIV1 (Kim et al., 2016). As demais similaridades são características comportamentais e sociais, para as quais a análise não está no escopo desta pesquisa.

Há indícios que demonstram a importância dos dividendos no valor da empresa, dado que o grupo das empresas que não distribuem dividendos a seus acionistas ser o de pior avaliação de mediana, havendo um tipo de relação mais semelhante a uma relação linear, quando analisadas as medianas dos grupos na Figura 3. Desta forma, a hipótese H1 é rejeitada. Assim, são fortalecidos os indícios da relevância dos dividendos no valor das empresas no mercado brasileiro. Este comportamento pode ser advindo da incerteza do futuro do mercado, conforme Lintner (1956) e Gordon (1963), da sinalização ao investidor, pela manutenção das taxas e periodicidades de distribuição de dividendos no mercado brasileiro (Galvão et al., 2018), da preferência do investidor pelo consumo do dividendo (Shefrin \& Statman, 1984), ou pela atratividade de taxas de juros externas ao mercado, conforme Lintner (1956).

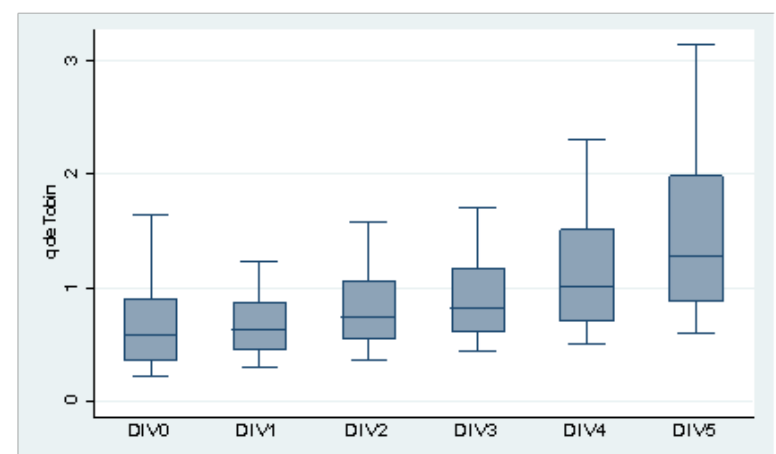

Figura 2 Formato da relação entre DIV e q de Tobin, no mercado brasileiro, por grupo DIVx, no período de 1996 a 2018.

Nota. Fonte: elaborado pelos autores. Devido à presença maciça de outliers, unicamente para efeito ilustrativo os dados utilizados para a apresentação dos gráficos box-plot foram winsorizados em $10 \%$ em cada extremidade. Contudo, os valores dos quartis inferiores e superiores e das medianas não foram afetados.

Ainda, pode ser relacionado aos postulados de Shefrin \& Statman (1984), para os quais a preferência dos investidores por dividendos tende a aumentar conforme a idade. Do total de investidores Pessoa Física na Bolsa brasileira, 46,90\% apresentam idade superior a 46 anos, detendo $82,82 \%$ do total de recursos investidos em 2018 (B3, 2018). Além disso, o maior pagamento de dividendos é apontado como mitigador dos problemas da agência oriundos da concentração acionária no mercado brasileiro (Galvão et al., 2019).

\subsection{Relação entre distribuição de dividendos e valor das empresas}

A análise foi realizada com uma regressão com efeitos fixos com erro-padrão robusto clusterizado, com dados em painel, conforme os resultados dos testes de Chow, Breusch-Pagan e de Hausmann, para se obter a análise de toda a amostra e o efeito dos grupos sobre o valor q das empresas (Tabela 4). 
Tabela 4. Resultados da relação entre os dividendos e o valor das empresas listadas na B3, de 1996 a 2018

\begin{tabular}{|c|c|c|c|c|}
\hline \multirow{2}{*}{$\frac{q \text { de Tobin }}{D I V}$} & \multicolumn{3}{|c|}{ Coeficientes e Valores de $p$} & \multirow{2}{*}{$\begin{array}{c}\text { Erro Padrão Robusto } \\
1,0413\end{array}$} \\
\hline & & $917^{* *}$ & $(0,036)$ & \\
\hline EBITDA & \multicolumn{2}{|c|}{$.0,3634$} & $(0,122)$ & 0,2344 \\
\hline RETE & \multicolumn{2}{|c|}{$1,7350 * * *$} & $(0,000)$ & 0,4684 \\
\hline$C V$ & \multicolumn{2}{|c|}{$0,4088 * * *$} & $(0,000)$ & 0,1097 \\
\hline$R O A$ & \multicolumn{2}{|c|}{0,0020} & $(0,756)$ & 0,0066 \\
\hline$T A$ & \multicolumn{2}{|c|}{$-1,1188^{* * *}$} & $(0,001)$ & 0,3361 \\
\hline $\mathrm{CASH}$ & \multicolumn{2}{|c|}{$0,6163^{*}$} & $(0,100)$ & 0,3735 \\
\hline INV & \multicolumn{2}{|c|}{$.0,1356$} & $(0,445)$ & 0,1773 \\
\hline AlaFIN & \multicolumn{2}{|c|}{$-0,0006$} & $(0,139)$ & 0,0004 \\
\hline EST & \multicolumn{2}{|c|}{0,5738} & $(0,360)$ & 0,6255 \\
\hline DIV1 & \multicolumn{2}{|c|}{$0,0943^{*}$} & $(0,071)$ & 0,0519 \\
\hline DIV2 & \multicolumn{2}{|c|}{$0,1428 * *$} & $(0,037)$ & 0,0680 \\
\hline DIV3 & \multicolumn{2}{|c|}{$0,1257^{*}$} & $(0,076)$ & 0,0704 \\
\hline DIV4 & \multicolumn{2}{|c|}{$0,2222 * * *$} & $(0,006)$ & 0,0797 \\
\hline DIV5 & \multicolumn{2}{|c|}{$0,2086^{*}$} & $(0,053)$ & 0,1072 \\
\hline Cons. & \multicolumn{2}{|c|}{$8,0342^{* * *}$} & $(0,000)$ & 2,1497 \\
\hline $\mathbf{N}$ & \multicolumn{2}{|c|}{1.831} & Grupos & 234 \\
\hline \multirow{3}{*}{$\mathbf{R}^{2}$} & Geral & 0,1529 & Prob.>F & 0,000 \\
\hline & Between & 0,0453 & \multirow{2}{*}{$F(15.233)$} & 687 \\
\hline & Overall & 0,0595 & & $0,8 /$ \\
\hline
\end{tabular}

Em que: q de Tobin é a relação entre o valor de mercado das ações e o valor das dívidas totais de uma empresa divididos pelo seu ativo total; DIV é o valor total de dividendos e de juros sobre capital próprio distribuídos por uma empresa em um ano $t$, divididos pelo seu ativo total; EBITDA é a diferença entre dois anos [t - $(t-1)]$ do EBITDA de uma empresa, dividida pelo seu ativo total do ano $t$; RETE é a diferença entre dois anos [t $-(t-1)]$ da reserva de lucros de uma empresa, dividida pelo seu ativo total do ano $t$; é a diferença entre dois anos [t -(t-1)] do EBITDA de uma empresa, dividida pelo seu ativo total do ano t; CV é é a diferença entre dois anos [ $t-(t-1)]$ da receita de uma empresa, dividida pelo seu ativo total do ano t; ROA é o retorno sobre o ativo da empresa no ano t; TA é o logaritmo do ativo total de uma empresa no ano t; CASH é a razão do total de disponibilidades de uma empresa pelo seu ativo total, no ano t; INV é a diferença entre dois anos [t - $(t-1)]$ do ativo total de uma empresa, dividida pelo seu ativo total do ano t; AlaFIN é a alavancagem financeira de uma empresa no ano t; EST é a razão entre os estoques declarados e o ativo total de uma empresa, no ano t; DIVI-5 são variáveis dummies que indicam os grupos de pagadores de dividendos DIVx.

Nota. Fonte: elaborado pelos autores. Significância: $1 \%\left({ }^{* *}\right), 5 \%\left({ }^{* *}\right)$ e $10 \%$ (*).

Os resultados obtidos consolidam a existência de diferença estatística entre os grupos $D / V x$. Mantidas todas as demais variáveis inalteradas, o valor médio das empresas pagadoras de dividendos é maior do que o das empresas não pagadoras de dividendos (DIVO, considerado como base para as dummies de grupos $\mathrm{DIVx}$ ). Também, nota-se que DIV2 é superior ao grupo suprimido e que DIV4 é superior a DIV2. Além disso, há significância estatística e relação positiva entre a variável $D I V$ e o valor da empresa $q$ de Tobin. Logo, a conclusão é de não rejeição da hipótese $H 2$, de relação direta entre os dividendos e o valor das empresas. Portanto, um pagamento de maiores dividendos, ceteris paribus, gera aumento no valor das empresas, conforme já relatado em Baskin (1989) e Gentry et al. (2003) e nos postulados de Lintner (1956) e Gordon (1963), Shefrin e Statman (1984) e Ehrahrdt e Brigham (2014).

A explicação da melhor avaliação dos grupos está ligada à relação direta dos dividendos com o valor das empresas. Isto explica, portanto, a relação de valor encontrada entre os grupos DIVx. Empresas que não distribuem dividendos (DIVO) são as de pior avaliação pelo mercado, enquanto mesmo empresas com pequenas distribuições de dividendos (DIV1 e DIV2) são melhor avaliadas. No outro extremo da análise, as empresas que efetuam a maior distribuição proporcional de lucros aos acionistas (DIV5) possuem maior valor.

Essa relação de preferência pelos dividendos pode ser explicada pela diminuição do risco e incerteza futura com o retorno do investimento (DeAngelo et al., 2008; Gordon, 1963; Lintner, 1956); pela preferência dos dividendos para consumo imediato, evidenciando uma clientela para os dividendos (Bräuer et al., 2020; Shefrin \& Statman, 1984), ou pelo ganho superior aos juros de mercado (Lintner, 1956). Além disso, a característica de idade corrobora os postulados de Shefrin e Statman (1984). Logo, é reforçada a explicação de que há evidente presença de questões comportamentais permeando a preferência por dividendos, conforme já pontuaram Miller e Modigliani (1961) e Baker e Weigland (2015).

Outro ponto que reforça a preferência por dividendos é o resultado de Loss e Sarlo Neto (2006), que afirmam que as empresas brasileiras não alteram sua política de dividendos frente à necessidade de investimentos, evitando diminuir ou cessar os retornos fixos para os acionistas. Kim et al. (2016) perceberam tal constatação no México, país com mercado de ações semelhante ao brasileiro. Galvão et al. (2018) confirmaram o estudo de 2006 - as empresas tendem a manter o pagamento estável de $25 \%$ do lucro líquido como dividendos mínimos, para garantir a presença do acionista e a valoração do mercado. Ainda as companhias evitam alterar a sua políitica de dividendos, mantendo a forma de remuneração e o nível de payout.

A relação positiva e significante de $C V$ evidencia a relação entre o crescimento de vendas e a valorização das empresas, podendo ser interpretada como oportunidades de crescimento (Ehrhardt \& Brigham, 2014), como reflexo positivo dos investimentos passados ou como sinal de criação de valor para os acionistas (Rappaport, 2001). Essa relação também pode denotar uma mitigação de conflitos de agência, e essa 
ser uma proxy para o crescimento da empresa, necessitando de captação de recursos externos e submetida à avaliação de mercado (Baker \& Powell, 1999; Easterbrook, 1984; Harada \& Nguyen, 2006; Hardin \& Hill, 2008; Holder et al., 1998; Lloyd et al., 1985), embora essa possibilidade pareça conflitante com os resultados da variável RETE.

A variável RETE apresenta relação positiva, sinalizando uma predileção do investidor para empresas que retenham parte de seu resultado, ao invés de distribuí-lo aos sócios. Uma interpretação é de que a retenção de lucros é uma tendência das empresas brasileiras, conforme Vancin e Procianoy (2016) descreveram, dada a escassez de recursos disponíveis para captação. Logo, uma vez que esse é um comportamento esperado de mercado, essa variável não forneceria elementos para compreender o fenômeno analisado. Desse modo, também se infere que não há evidências da distribuição de dividendos como mecanismo de controle dos conflitos de agência (Vancin \& Procianoy, op. cit.). Este resultado se mostra oposto ao relatado por Silva e Albanez (2017), para os quais empresas com maiores retenções de lucro para reinvestimento não foram eficientes na criação de valor para os acionistas através de investimentos.

O TA apresenta uma relação contrária ao relatado na literatura (Silva Jr. \& Machado, 2015; Allen \& Rachim, 1996). Acreditava-se que empresas maiores seriam percebidas como aquelas com menores oportunidades de investimento, distribuindo seu lucro como dividendos, o que elevaria o seu valor de mercado, sendo esta sua relação descrita com os dividendos na literatura (Santos \& Galvão, 2015; Fama \& French, 2001). Uma explicação para a relação negativa observada seria a expectativa de ganho futuro oriunda de empresas menores e, portanto, com maiores oportunidades de crescimento, como relatado no estudo da distribuição de dividendos de Fama e French (2001), da mesma forma como no trabalho sobre a precificação de empresas americanas, por Kim et al. (2016), que corroboraria a teoria de Miller e Modigliani (1961). Outra interpretação seria de que os investidores estariam buscando empresas mais eficientes, que conseguissem maior produtividade e lucratividade com menores recursos disponíveis.

Dois pontos, contudo, não corroboram com esse argumento. Em primeiro lugar, percebe-se que, diferentemente do mercado americano em que há uma modificação no cenário, com a introdução de empresas menores (Fama \& French, 2001), não há variação significativa no tamanho das empresas no período estudado. Também, a aceitação do argumento da eficiência é rejeitada quando se nota o maior score de $R O A(0,756)$ e de $\operatorname{EBITDA}(0,122)$, que demonstra não haver significância estatística entre estas variáveis e $\circ$ valor das empresas, para o presente modelo de estudos adotado.

\section{Considerações finais}

Os resultados demonstraram que as empresas que não distribuem parcelas de seus lucros para os detentores de ações são piores avaliadas pelo mercado, enquanto as avaliações dos grupos são melhores quando há maiores distribuições de dividendos. Os dados permitiram a rejeição da $\mathrm{H}_{1}$, com a não existência do "Formato J" no mercado brasileiro. Esse achado pode indicar a presença de um mercado que não absorve informações ou características não observáveis das empresas, não valorando presentemente a não distribuição de dividendos como uma oportunidade de ganho futuro. Em mercados mais desenvolvidos, como o norte-americano, o "Formato J" ocorre, como uma possível confiança de que os dividendos voltarão ou serão ainda melhores do que os distribuídos anteriormente.

Ratificando-se a rejeição de $\mathrm{H}_{1}$, foi realizada uma regressão com dados em painel para os grupos $D I V x$. Os resultados obtidos permitiram afirmar a existência de relação estatística significante e positiva entre os dividendos e o valor das empresas no mercado brasileiro, não rejeitando a $\mathrm{H}_{2^{\prime}}$ além de demonstrar que há um escalonamento de valores entre os grupos, conforme a estatística descritiva demonstrara. Porém, mantém-se a ideia de que o mercado nacional valora dividendos e resultados positivos, enquanto os negativos podem ser vistos como condições insuficientes das empresas. No Brasil, qualquer valor de dividendo parece confirmar o efeito clientela e o "Efeito Disposição".

A relevância dos dividendos no valor das empresas ainda é explicada mediante a incerteza com o futuro dos investimentos, conforme postularam Lintner (1956) e Gordon (1963), a preferência pelo consumo imediato, além do fator comportamento por idade, conforme proposto por Shefrin e Statman (1984), a concorrência pelo investimento com fontes externas pagadoras de juros, como investimentos financeiros ou títulos públicos, conforme Lintner (1956) e questões do mau uso dos recursos por parte dos gestores, conforme a Teoria de Agência, de Jensen e Meckling (1976). No Brasil, a eficiência de mercado ainda é baixa, bem como há uma tendência elevada em os acionistas incorporarem informações com alto gerenciamento de resultados, dando baixa relevância para empresas que não distribuem dividendos, levando a valorações subavaliadas em algumas situações.

A presente pesquisa é contributiva por considerar a presença de empresas com políticas distintas de distribuição de lucros, analisando-as sob o prisma das teorias de dividendos. Ademais, apresentam-se novos métodos de análise da 
relação dividendos e valor, por meio da segmentação da amostra. Com isso, tinha-se a ideia de que o "Formato J" pudesse ocorrer no mercado acionário do país. No entanto, permanece-se a lógica de que o dividendo importa para o acionista ao valorar as ações da firma. Tal constatação pode não reconhecer os intangíveis, a exemplo, que as empresas têm e poderão gerar valores favoráveis no futuro. Então, nos resultados desta pesquisa, não distribuir dividendos parece indicar que há normalmente a associação recorrente com prejuízos.

Menciona-se que o mercado acionário brasileiro ainda é pequeno e novo em comparação a outros países desenvolvidos. Porém, elementos como não tributação dos dividendos e juros sobre o capital próprio trazem diferenças e podem, de alguma maneira, não causar percepções diferenciadas em não distribuir os lucros e dividendos menores ou maiores. Nesse cenário, talvez possa se discutir que o ambiente informacional do país ainda está evoluindo ou os acionistas deixam de considerar informações importantes (ou as más-precificam). Acredita-se que com a adoção das International Financial Reporting Standards (IFRS) e as possíveis reformas tributárias que afetarão os dividendos, o "Formato J" possa ocorrer.

Em palavras complementares, como contribuição, discorrese que mercados como o do Brasil seguem a tendência da relevância dos dividendos, como verificado por Kim et al. (2016) no México. Nações assim são caracterizadas por acionistas com exigências de curto prazo, imediatismo (mas normalmente avessos ao risco), e longo prazo não planejado ou esperado.

Apesar dos avanços descritos, há limitações. Em primeiro lugar, ela se baseia em dados quantitativos, o que não permite descrever 0 comportamento do investidor frente às políticas de dividendos. Outrossim, há a limitação de não generalização, que faz com que o estudo seja restrito a um tipo de observação e análise específica. Por fim, há limitações de dados, notadamente para períodos pré-1996, o que reduziu a amostra, e consequentemente, os achados. No entanto, essas dificuldades não invalidam a pesquisa.

Logo, há férteis campos de estudos para o tema. As sugestões de estudos abrigam pesquisas de cunho qualitativoquantitativo, que possam relacionar os achados estatísticos à análise comportamental de investidores e gestores. Também se recomenda o uso de outras variáveis para a interpretação da relação, e a análise exclusiva de empresas que não distribuem dividendos.

\section{Referências}

Allen, D. E., \& Rachim, V. S. (1996). Dividend policy and stock price volatility: Australian evidence. Applied Financial Economics, 6(2), 175-188, doi: https://doi. org/10.1080/096031096334402.

Baker, H. K., Powell, G. E., \& Veit, E. T. (2002). Revisiting the dividend puzzle: Do all of the pieces now fit? Review of Financial Economics, 11 (4), 241-261, doi: https://doi. org/10.1016/S1058-3300(02)00044-7.

Baker, H. K., \& Powell, G. E. (1999). How corporate managers view dividend policy. Quarterly Journal of Business and Economics, 38(17), 17-35. Recuperado em 26 março, 2019 , de www.jstor.org/stable/40473257.

Baker, H. K., \& Weigand, R. (2015). Corporate Dividend Policy Revisited. Managerial Finance, 41(2), 126-144, doi: https://doi.org/10.1 108/MF-03-2014-0077.

Baker, M., \& Wurgler, J. (2004). A catering theory of dividends. The Journal of Finance, 59(3), $1125-1165$, doi: https://doi.org/10.1111/j.1540-6261.2004.00658.x.

Baskin, J. (1989). Dividend policy and the volatility of common stock. Journal of Portfolio Management, 15(3), 19-25, doi: https://doi.org/10.3905/ipm.1989.409203

Beaver, W. H., Mcanally, M. L., \& Stinson, C. H. (1997). The Informational Content of Earnings and Prices: A simultaneous Equations Approach. Journal of Accounting and Economics, 23(1), 53-81, doi: https://doi. org/10.1016/S0165-4101(96)00424-7.

Bezawada, B., \& Tati, R. K. (2017). Dividend policy and firm valuation - a study of Indian electrical equipment manufacturing industry. Theoretical Economics Letter, 7, 1233-1243, doi: https://doi.org/10.4236/ tel.2017.75083.

Black, F. (1976). The dividend puzzle. Journal of Portfolio Management, 2(2), 5-8, doi: https://doi.org/10.3905/ ipm. 1976.408558.

Black, F., \& Scholes, F. (1974). The Effects of Dividend Yield and Dividend Policy on Common Stock Prices and Returns. Journal of Financial Economics, 1(1), 1-22, doi: https://doi.org/10.1016/0304-405X(74)90006-3 
Brasil. Lei n. 9.249, de 26 de dezembro de 1995. Recuperado em 26 novembro, 2018, de www.planalto.gov.br.

Bräuer, K., Hackethal, A., \& Hanspal, T. (2020). Consuming dividends, SAFE Working Paper, 280, Leibniz Institute for Financial Research SAFE, doi: http://dx.doi. org/10.2139/ssrn.3466731.

Camargos, M. A., Salvto, M. A., Camargos, M. C. S. (2012). Determinantes do Dual-Class Premium de Companhias Brasileiras em Anos Recentes. Anais do XXXVI EnANPAD. Recuperado em 22 setembro, 2018, de http:// www.anpad.org.br/admin/pdf/2012_FIN2023.pdf.

Carvalho, C. A. e Ribeiro, E. M. S. (2019). Shareholding Interest in Companies Listed on B3 in 2018: A Study of Networks. Brazilian Business Review, 16(5), 519-536, doi: https://doi.org/10.15728/bbr.2019.16.5.6.

Correia, L. F., \& Amaral, H. F. (2002). O impacto da política de dividendos sobre a rentabilidade de títulos negociados na Bovespa no período de 1994 a 2000. Anais do Encontro da Associação Nacional de Pósgraduação e Pesquisa em Administração, 26.

DeAngelo, H., \& DeAngelo, L. (2006). The irrelevance of the MM dividend irrelevance theorem. Journal of Financial Economics, 79, 293-315, 2006, doi: https://doi. org/10.1016/i.jfineco.2005.03.003.

DeAngelo, H., DeAngelo, L., \& Skinner, D. J. (2008). Corporate Payout Policy. Foundations and Trends in Finance, 3(2-3), 95-287, doi: https://doi. org/10.1561/0500000020.

Dhaliwal, D., Erickson, M., \& Trezevant, R. (1999). A test of the theory of tax clienteles for dividend policies. National Tax Jounal, 52(2), 179-194. Recuperado em 20 dezembro, 2018, de https://www.jstor.org/stable/41789388.

Easterbrook, F. H. (1984). Two agency-cost explanations of dividends. American Economic Review, 74(4), 650659. Resgatado em 26 março, 2019, de www.jstor.org/ stable/1805130.

Ehrhardt, M. C., \& Brigham, E. F. (2014). Administração financeira: teoria e prática. São Paulo: Cengage Learning.

Elton, E. J., \& Gruber, M. J. (1970). Marginal stockholder tax rate and the clientele effect. The Review of Economics and Statistics, 52(1), 68-74, doi: https://doi. org/10.2307/1927599.
Fama, E. F., \& French, K. R. (1998). Taxes, Financing Decisions, and Firm Value. The Journal of Finance, 53(3), 819-843. Recuperado em 19 outubro, 2018, de https:// www.jstor.org/stable/117379.

Fama, E. F., \& French, K. R. (2001). Disappearing Dividends: Changing Firm Characteristics or Lower Propensity to Pay? Journal of Financial Economics, 60, 3-43, doi: http:// dx.doi.org/10.1016/S0304-405x(01)00038-1.

Farrelly, G. E., \& Baker, H. K. (1989). Corporate dividends: views of institutional investors. Akron Business and Economic Review, 20, 89-100. Recuperado em 5 maio, 2020, de www.questia.com/library/journal/1G1-7690617/ corporate-dividends-views-of-institutional-investors.

Ferreira Junior, W. O., Nakamura, W. T., Martin, D. M. L., \& Bastos, D. D. (2010). Evidências empíricas dos fatores determinantes das políticas de dividendos das firmas listadas na Bovespa. FACEF, 13(2). Recuperado em 9 março, 2019, de www.academia.edu/30716999/ Evid\%C3\%A Ancias_Emp\%C3\%ADricas_Dos_Fatores_ Determinantes_Das_Pol\%C3\%ADticas_De_Dividendos_ Das_Firmas_Listadas_Na_Bovespa.

Forti, C. A. B., Peixoto, F. M., \& Alves, D. L. (2015). Fatores determinantes do pagamento de dividendos no Brasil. Revista Contabilidade \& Finanças, 26(68), 167-180, doi: https://doi.org/10.1590/1808-057×201512260.

Galvão, K. S., Santos, J. F., \& Araújo, J. M. (2018). Dividendos, juros sobre capital próprio e níveis de payout: Um estudo investigativo sobre a política de distribuição de dividendos adotada pelas empresas listadas na BM\&FBovespa. Revista Contemporânea de Contabilidade, 15(36), 03-30, doi: http://dx.doi.org/10.5007/2175$8069.2018 \mathrm{v} 15 \mathrm{n} 36 \mathrm{p} 3$

Galvão, K. S., dos Santos, J. F., \& de Araújo, J. M. (2019). Política de Distribuição de Dividendos: uma análise dos fatores relacionados ao pagamento de dividendos e do payout incremental pelas empresas brasileiras. Enfoque: Reflexão Contábil, 38(3), 57-75, doi: https://doi. org/10.4025/enfoque.v38i3.42438

Gentry, W. M., Kemsley, D., \& Mayer, C. J. (2003). Dividend Taxes and Share Prices: Evidence from Real Estate Investment Trusts. The Journal of Finance, 58(1), 261-282, doi: https://doi.org/10.1111/1540-6261.00524.

Gordon, M. J. (1959). Dividends, earning, and stock prices. Review of Economics and Statistics, 41 (2), 99-105, 
doi: https://doi.org/10.2307/1927792.

Gordon, M. J. (1963). Optimal investment and financing policy. Journal of Finance, 18(2), 264-272, doi: https:// doi.org/10.2307/2977907.

Grando, T., Brunozi Júnior, A. C., Gomes Machado, D., \& Zanini, F. (2016). Empresas Dual Class: Um estudo do impacto no valor das empresas Brasileiras. Enfoque: Reflexão Contábil, 35(2), 67-86, doi: https://doi. org/10.4025/enfoque.v35i2.30016.

Gugler, K., \& Yurtoglu, B. B. (2003). Corporate governance and dividend pay-out policy in Germany. European Economic Review, 47(4), 731-758, doi: https:// doi.org/10.1016/S0014-2921(02)00291-X.

Harada, K., \& Nguyen, P. (2006). Ownership concentration, agency conflicts, and dividend policy in Japan. Journal of Finance, 55, 1-33, doi: https://doi. org/10.2139/ssrn. 953433 .

Hardin, W., \& Hill, M. D. (2008). REIT Dividend determinants: excess dividends and capital market. Real Estate Economics, 36(2), 349-369, doi: https://doi. org/10.1111/j.1540-6229.2008.00216.x.

Holder, M. E., Langrehr, F. W., \& Hexter, J. L. (1998). Dividend policy determinants: an investigation of the influences of the stakeholder theory. Financial Management, 27(3), 73-82, doi: https://doi.org/10.2307/3666276.

Jensen, M. C., \& Meckling, W. H. (1976). Theory of the firm: managerial behavior, agency costs and ownership structure. Journal of Financial Economics, 3(4), 305-360, doi: https://doi.org/10.1016/0304-405X(76)90026-X.

Kammler, E. L., \& ALVES, T. W. (2004). A teoria do "q" de Tobin e a previsão dos gastos com investimentos: um estudo com empresas brasileiras de capital aberto. Encontro da Associação Nacional dos Programas de Pós-Graduação em Administração (EnANPAD), Curitiba. Resgatado em 28 novembro, 2018, de www.anpad.org.br/admin/pdf/ enanpad2004-ccg- 1633.pdf.

Kim, S., Park, S. H., \& Suh, J. (2016). A J-shapped crosssectional relationship between dividends and firm value. Journal of Corporate Finance, 48(1), 857-877, doi: https:// doi.org/0.1016/i.jcorpfin.2016.09.010.

Lintner, J. (1956). Distribution of incomes of corporations among dividends, retained earnings and taxes. American
Economic Review, 46(2), p. 97-113. Resgatado em 20 agosto, 2018, de https://www.jstor.org/stable/ $\mathrm{pdf} / 1910664 . \mathrm{pdf}$.

Litzenberger, R. H., \& Ramaswamy, K. (1982). The Effects of Dividends on Common Stock Prices Tax Effects or Information Effects? The Journal of Finance, 37(2), 429 443, doi: https://doi.org/10.2307/2327346.

Lloyd, W. P., Jahera, J. S., \& Page, D. E (1985). Agency costs and dividend payout ratios. The Financial Review, 20(3), 78 78, doi: https://doi.org/10.1111/j.1540-6288.1985. tb00256.x.

Loss, L., \& Sarlo Neto, A. (2006). O Inter-relacionamento entre Políticas de Dividendos e de Investimentos: Estudo Aplicado às Companhias Brasileiras Negociadas na Bovespa. Revista de Controladoria e Finanças, 40(1), 52-66, doi: https://doi.org/10.1590/\$1519. 70772006000100005 .

Marques, T. A., Guimarães, T. M., \& Peixoto, F. M. (2015). A concentração acionária no Brasil: análise dos impactos no desempenho, valor e risco das empresas. Revista de Administração Mackenzie, 16(4), 100-133, doi: https:// doi.org/10.1590/167869712015/administracao. v16n4p100-133

Martins, A. I., \& Famá, R. (2012). O que revelam os estudos realizados no Brasil sobre política de dividendos? Revista de Administração de Empresas, 52(1), 24-39, doi: https:// doi.org/10.1590/S0034-75902012000100003.

Miller, M. H., \& Modigliani, F. (1961). Dividend Policy, Growth, and the Valuation of Shares. The Journal of Business, 34(4), 41 1-433. Recuperado em 12 novembro, 2018, de www.jstor.org/stable/2351143.

Modigliani, F., \& Miller, M. H. (1963). Corporate income taxes and the cost of capital: A correction. American Economic Review, 53(3), 422-443. Resgatado em 13 agosto, 2018, de www2.bc.edu.

Moser, W. J., \& Puckett, A. (2009). Dividend Tax Clienteles: Evidence from Tax Law Changes. The Journal of the American Taxation Association, 31(1), 1-22, doi: https://doi.org/10.2308/jata.2009.31.1.1.

Naranjo, A., Nimalendran, M., \& Ryngaert, $M$. (1998). Stock Returns, Dividend Yields, and Taxes. The Journal of Finance, 53(6), 2029-2057, doi: https://doi. org/10.1111/0022-1082.00082. 
Nogueira, B., Avelino, B., Colares, A., \& Reis, D. (2021). Índice de sentimento do investidor no mercado de ações brasileiro. Revista Contabilidade e Controladoria, 12(3), doi: http://dx.doi.org/10.5380/rcc.v12i3.71338.

Pinkowitz, L., Stulz, R., \& Williamson, R. (2006). Does the Contribution of Corporate Cash Holdings and Dividends to Firm Value Depend on Governance? A Cross-country Analysis. The Journal of Finance, 61(6), 2725-2751, doi: https://doi.org/10.1111/i.1540-6261.2006.01003.x.

Procianoy, J. L., \& Verdi, R. S. (2003). O efeito clientela no mercado brasileiro: será que os investidores são irracionais? Revista Brasileira de Finanças, 2(1), 217-242. https://lume.ufrgs.br/handle/10183/196623

Rappaport, A. (2001). Gerando valor para o acionista. São Paulo: Atlas.

Ribeiro, A. (2010). Determinantes da política de dividendos: evidência empírica para as empresas não financeiras cotadas na Euronext Lisbon. Revista Portuguesa e Brasileira de Gestão, 9(1-2), 15-25. Resgatado em 30 abril, 2019, de www.scielo.mec.pt/scielo.php?script=sci_ arttext\&pid $=$ S1645-44642010000100003.

Rodrigues, R. L., \& Ambrozini, M. A. (2016). Teoria de Agência e políticas de dividendos: evidências nas empresas brasileiras de capital aberto no período de 2000 a 2013. Anais do XLIII Encontro Nacional de Economia. Rio de Janeiro, ANPEC, 43.

Ross, S. A., Westerfield, R. W., \& Jaffe, J. F. (2008). Administração Financeira. ( $2^{a}$. ed, $7^{a}$. reimp.). São Paulo: Atlas.

Santos, J. F., \& Galvão, K. S. (2015). Política de dividendos e seus fatores determinantes: evidenciando a ausência de consenso teórico-empírico. Revista FAE, 18(1), 52-69. Recuperado em 22 novembro, 2019, de https://revistafae. fae.edu/revistafae/article/view/31.
Shefrin, H. M., \& Statman, M. (1984). Explaning investor preference for cash dividends. Journal of Financial Economics, 13(2), 253-282. https://doi. org/10.1016/0304-405X(84)90025-4.

Shleifer, A., \& Vishny, R. (1986). Large shareholders and corporate control. Journal of Political Economy, 94, 461488. Resgatado em 30 agosto, 2018, de www.jstor.org/ stable/1833044.

Silva, A. O., \& Dantas, J. A. (2015). Impacto da Política de Dividendos no Valor de Mercado das Instituições Financeiras no Brasil. Revista de Gestão, Finanças e Contabilidade, 5(4), 43-63, doi: http://dx.doi. org/10.18028/2238-5320/rgfc.v5n4p43-63.

Silva, L. C., \& Albanez, T. (2017). Impacto dos lucros retidos sobre a criação de valor para o acionista de companhias abertas brasileiras. Enfoque: Reflexão Contábil, 36(3), 15-32, doi: https://doi.org/10.4025/ enfoque.v36i3.34455.

Silva Júnior, C. P., \& Machado, M. A. (2015). A influência da política de dividendos sobre a volatilidade das ações. Revista de Contabilidade e Controladoria, 7(3), 8-20, doi: https://doi.org/10.5380/rcc.v7i3.36698.

Van Horne, J. C. (1998). Financial management and policy (1 ed.). New Jersey: Prentice-Hall.

Vancin, D. F., \& Procianoy, J. L. (2016). Os Fatores Determinantes do Pagamento de Dividendos: o Efeito do Obrigatório Mínimo Legal e Contratual nas Empresas Brasileiras. Revista Brasileira de Finanças, 14(1), 89-123. Recuperado em 17 julho, 2018, de www.lume.ufrgs.br.

Zanon, A. R. M., Araújo, C. G., \& Nunes, A. (2017). Influência da Política de Dividendos no Valor de Mercado das Empresas Brasileiras. Revista de Gestão, Finanças e Contabilidade, 7(3), 326-339, doi: https://doi. org/10.18028/rgfc.v7i3.3844. 